\title{
Endogenous Antimicrobial Peptide Expression in Response to Bacterial Epidermal Colonization
}

\author{
Michael Brandwein ${ }^{1,2}$, Zvi Bentwich ${ }^{2}$ and Doron Steinberg ${ }^{1 *}$ \\ 'Biofilm Research Laboratory, Faculty of Dental Medicine, Hebrew University of Jerusalem, Hadassah Ein Kerem, \\ Jerusalem, Israel, ${ }^{2}$ Cutaneous Microbiology Laboratory, The Skin Research Institute, Dead Sea and Arava Science \\ Center, Masada, Israel
}

Bacterial commensal colonization of human skin is vital for the training and maintenance of the skin's innate and adaptive immune functions. In addition to its physical barrier against pathogen colonization, the skin expresses a variety of antimicrobial peptides (AMPs) which are expressed constitutively and induced in response to pathogenic microbial stimuli. These AMPs are differentially effective against a suite of microbial skin colonizers, including both bacterial and fungal residents of the skin. We review the breadth of microorganism-induced cutaneous AMP expression studies and their complementary findings

Juarez Antonio Simões Quaresma, Universidade Federal do

Pará, Brazil

Reviewed by:

Osmar Nascimento Silva,

Universidade Católica

Dom Bosco, Brazi

Rongxin Su,

Tianjin University, China

Vijaykumar Patra,

Medical University of Graz, Austria

Ulvi Kahraman Gürsoy,

University of Turku, Finland

${ }^{*}$ Correspondence:

Doron Steinberg

dorons@ekmd.huji.ac.il

Specialty section: This article was submitted to Microbial Immunology, a section of the journal

Frontiers in Immunology

Received: 14 September 2017 Accepted: 09 November 2017 Published: 27 November 2017

Citation:

Brandwein M, Bentwich Z and Steinberg D (2017) Endogenous Antimicrobial Peptide Expression

in Response to Bacterial Epidermal Colonization.

Front. Immunol. 8:1637. doi: 10.3389/fimmu.2017.01637 on the efficacy of skin AMPs against different bacterial and fungal species. We suggest further directions for skin AMP research based on emerging skin microbiome knowledge in an effort to advance our understanding of the nuanced host-microbe balance on human skin. Such advances should enable the scientific community to bridge the gap between descriptive disease-state AMP studies and experimental single-species in vitro studies, thereby enabling research endeavors that more closely mimic the natural skin environs.

Keywords: antimicrobial peptides, dermatology, microbial immunology, cathelicidin, human beta defensins, psoriasin

\section{INTRODUCTION}

Human skin is the largest epithelial layer and provides a vast surface area for the interaction between the host and environmental factors (1). The skin acts as the first line of defense against physical, chemical, and biological challenges (2). The epidermis, or the outermost layer of the skin comprised mostly of stratified keratinocytes, is the first to encounter external stimuli and is therefore equipped with an arsenal of immune-modulating activities (3). Microbial colonization of the skin, long recognized as an etiological factor in many skin diseases, has been shown to induce species-specific immune responses $(3,4)$. Antimicrobial peptides (AMPs) are critical elements of the skin's chemical barrier against pathogens due to their antibacterial and immunomodulatory properties (5).

Antimicrobial peptides have been discovered in a wide array of organisms and provide a first-line defense mechanism against pathogen colonization. Microbial-induced AMP expression on human skin was first reported in 1997 with the discovery of human $\beta$-defensin 2 (hBD2), a cationic peptide exhibiting broad spectrum antibiotic activity (6), in addition to cathelicidin LL-37 $(7,8)$. The list of skin-associated inducible AMPs has since expanded to include hBD3 (9), psoriasin (also referred to as S100A7) (10), and RNase 7 (11) in addition to the constitutively expressed dermcidin (12) and hBD1. Most AMP's carry a cationic charge, thereby allowing them to attach to the anionic parts of the bacterial membranes. Once attached, AMP's then take advantage of their amphipatic 
structure and disrupt the bacterial membrane by inserting their hydrophobic end into the bacterial membrane (13). While all of the AMPs listed above are expressed by keratinocytes, hBD2 can also be expressed by macrophages and dendritic cells, and LL-37 can be expressed by macrophages and neutrophils $(14,15)$. The ability of human skin to modulate bacterial colonization through the secretion of AMPs has direct consequences on the microbial landscape of the skin.

Microbial inhabitants of the skin have been of great interest as they affect skin homeostasis, and therefore are involved in important biological processes in both health and diseased states. Traditional cutaneous microbiology has focused on Staphylococcus epidermidis, Staphylococcus aureus, and Propionibacterium acnes, yet expanding experimental techniques have shown that healthy skin is a habitat for a milieu of other microorganisms, including varied species in the Staphylococcus genus, Micrococcus luteus, Corynebacterium spp., Streptococcus mitis, Malassezia globosa, Malassezia restricta, and others (16-18). Microorganisms immobilized on skin can display biofilm-like properties, including virulence and resistance to antibiotics (19). Importantly, biogeography, or body site, drives microbial community composition, a factor often attributed to the different glands and secretions present in moist, sebaceous, and dry areas of the skin $(16,17)$. Resident microorganisms have been implicated in disease pathogenesis. For example, $S$. aureus infects the skin of atopic dermatitis individuals (20) and P. acnes colonization is an important etiological factor in acne vulgaris (21). Interestingly, AMP expression in situ is also linked to diseased states. Rosacea patients secrete elevated levels of cathelicidin (22), psoriasis patients upregulate a host of AMPs $(23,24)$ and atopic dermatitis skin expresses less hBD and cathelicidin than that of healthy individuals $(25,26)$. The former two research hypotheses grew out of the observation that psoriatic individuals rarely contract skin infections (23), while atopic dermatitis patients often suffer from skin infections $(27,28)$.

It is evidently clear that the human body and the microbiota that colonize its skin are in a constant state of attenuation. Microbemicrobe and human-microbe interactions mediate the events that determine both the amount and type of microorganisms that reside on the skin and the results of these exchanges have broad medical and cosmetic consequences. In this review, we summarize two decades of research devoted to the antimicrobial efficacy of skin AMPs and their ability to be induced by the cutaneous microbiota. We briefly touch upon associations between AMP expression and disease states [reviewed in Ref. (29)]. Additionally, we do not focus on the signaling or alarmin mechanisms of AMP expression [reviewed in Ref. (30)], but rather their antimicrobial capabilities. We conclude with an outlook toward future AMP research, with an emphasis on integrating microbiome-era knowledge into our understanding of AMP expression.

\section{EXPERIMENTAL MODELS FOR THE ASSESSMENT OF AMP EXPRESSION IN HUMAN SKIN}

Three main experimental models can be used to detect AMP expression on human skin: in vitro cell lines, ex vivo skin fragments and in situ biopsies. Keratinocyte cell lines, whether primary or commercial, provide the most readily accessible and easily manipulated medium for the study of skin-microbial interactions. Keratinocytes have the distinct advantage of being able to be maintained in the laboratory for extended periods of time and their availability does not hinge upon extralaboratory sources. However, cell lines are maintained submerged in media, thereby necessitating that any microbial growth be maintained within the cell culture medium. This poses two limitations: microorganisms capable of growth on human skin may not be sustained by cell culture media and submerged growth may induce physiological changes in the microorganism that are not present when grown on the skin-air interface. Additionally, keratinocytes allow for a two-dimensional modeling of the skin surface which lacks many of the biological and physical elements present in vivo (31). In addition to keratinocytes, sebocyte cell lines can serve as a model substrate for bacterial-induced AMP expression. However, immortalization of sebocytes has proven difficult, and therefore, their availability as a model platform is limited.

Human skin organ cultures, typically obtained following cosmetic surgeries, serve as an additional model for cutaneous-microbial interactions. Skin explants are advantageous for the research of skin-microbe interactions for a number of reasons: they contain all of the various elements of human skin including the dermis, epidermis, and associated appendages, and unlike keratinocytes, the surface topography of skin explants matches that of human skin. Additionally, microbial growth is sustained at the skin-air interface, similar to in vivo conditions. Disadvantages of the ex vivo model include its restricted availability and limited life-span [roughly 2 weeks sustained in culture (31)]. Additionally, skin fragments are obtained from a human donor and are therefore intrinsically not sterile. They can be treated with antibiotics and antifungals before inoculating with bacteria, however, resistant bacteria may remain viable, thereby interfering with experimental procedures. Finally, bacterial immobilization on skin explants is a poorly characterized method of bacterial growth, thereby limiting the conclusions that can be garnered from such experiments.

The final human model applicable for skin-microbial interactions is biopsies from individuals in diseased states whereby the disease has a known microbial etiological factor. Such biopsies can be useful for histological analysis and molecular studies, thereby establishing associations between microorganisms and disease states. However, these specimens are often not culturable and therefore their usefulness as a model is limited. As with any model system, complementary experiments using all models are the preferred path for approaching skin-microbe research hypotheses. Specifically, the availability of keratinocytes, the wealth of knowledge available in the literature regarding keratinocyte inoculates, and the ability to manipulate experimental conditions necessitates their inclusion in an experimental setup. Validation of observations made with keratinocytes can be done ex vivo with the skin explant model and finally in situ from relevant pathological specimens. 


\section{AMP's AND SKIN MICROORGANISMS}

\section{Staphylococcus aureus}

Skin-associated AMP expression and efficacy has been studied on a host of microorganisms, yet studies involving $S$. aureus are the most widespread (Summarized in Table 1). The first report of RNase 7 expression in human skin cells reported that challenging human primary keratinocytes with an inoculum of $S$. aureus leads to increased RNase 7 mRNA levels and that RNase 7 kills S. aureus in a dose-dependent manner (11). A subsequent study expanded upon these results and showed elevated RNase 7 secretion $2 \mathrm{~h}$ after challenging skin explants with an $S$. aureus inoculum. The study also showed that blocking RNase 7 activity in stratum corneum extracts and in skin explants hindered skin antimicrobial activity (32). Separately, anti-S. aureus activity of RNase 7 was shown in vitro (33) and secreted factors of $S$. aureus were shown to upregulate RNase 7 expression in primary keratinocytes (34).

In addition to the RNase 7 observations above, human beta-defensin activity against $S$. aureus has been studied as well. Several groups have documented increased expression of hBD2 $(6,34-36)$ and hBD3 $(34,35,37)$ in keratinocytes in response to inoculation with live $S$. aureus. Additionally, marked hBD2 and h-BD3 upregulation has been observed when inoculating keratinocytes with heat-killed $S$. aureus or $S$. aureus conditioned medium $(34,35,37,38)$. The hBD2 concentration needed to kill $100 \%$ S. aureus in vitro is $10 \mu \mathrm{g} / \mathrm{ml}$ (38) and its anti-S. aureus activity is increased in acidic conditions, similar to that of the skin (39). Furthermore, hBD2 works synergistically with a host of other compounds, including hBD3, lysozyme, and the serine protease Esp (39, 40). Additionally, Kisich et al. showed that constitutive, and not inducible, expression of hBD3 provides a level of clearance from $S$. aureus immediately upon infection (41).
Keratinocytes infected with $S$. aureus were shown to slightly overexpress the AMP LL-37 (38) and the anti-S. aureus activity of keratinocytes is partially dependent on cathelicidin expression (42). These experiments, along with the majority of the aforementioned AMP-S. aureus induction studies, were carried out solely on cultured keratinocytes.

\section{Staphylococcus epidermidis}

Staphylococcus epidermidis, the "helpful" Staphylococci, has also been shown to induce expression of several AMPs. Percoco et al. showed that $S$. epidermidis infection significantly upregulates hBD2 and hBD3, but not Psoriasin and RNase 7, expression in skin explants (43). A further study on keratinocytes supported these results and showed that hBD2 and hBD3 expression was stimulated by $S$. epidermidis infection and that this induction is mediated through TLR2 signaling (44). Wanke et al. reported upregulation of hBD2, hBD3, and RNase $724 \mathrm{~h}$ after S. epidermidis colonization of keratinocytes (34), whereas both Harder et al. and Dinulos et al. examined the keratinocyte expression solely of hBD2 following $S$. epidermidis inoculation, and determined that it was upregulated in response to the commensal $(6,36)$. Of note, the experimental conditions for the aforementioned observations may reflect a state of infection rather than commensal living of $S$. epidermidis on the skin.

\section{Propionibacterium acnes}

Propionibacterium acnes, classically regarded as a resident of the pilosebaceous unit, also has the ability to induce AMP expression. Nagy et al. showed that certain clinical strains of $P$. acnes induces hBD2 expression in keratinocytes (45). Subsequently, $P$. acnes supernatant was shown to induce the expression of hBD2 and LL-37 mRNA in keratinocytes (46). Unique among skin resident microorganisms, $P$. acnes-induced AMP expression has also been studied in sebocytes. P. acnes supernatant

TABLE 1 | Summary of experimental reports of Staphylococcus aureus-induced antimicrobial peptide (AMP) expression.

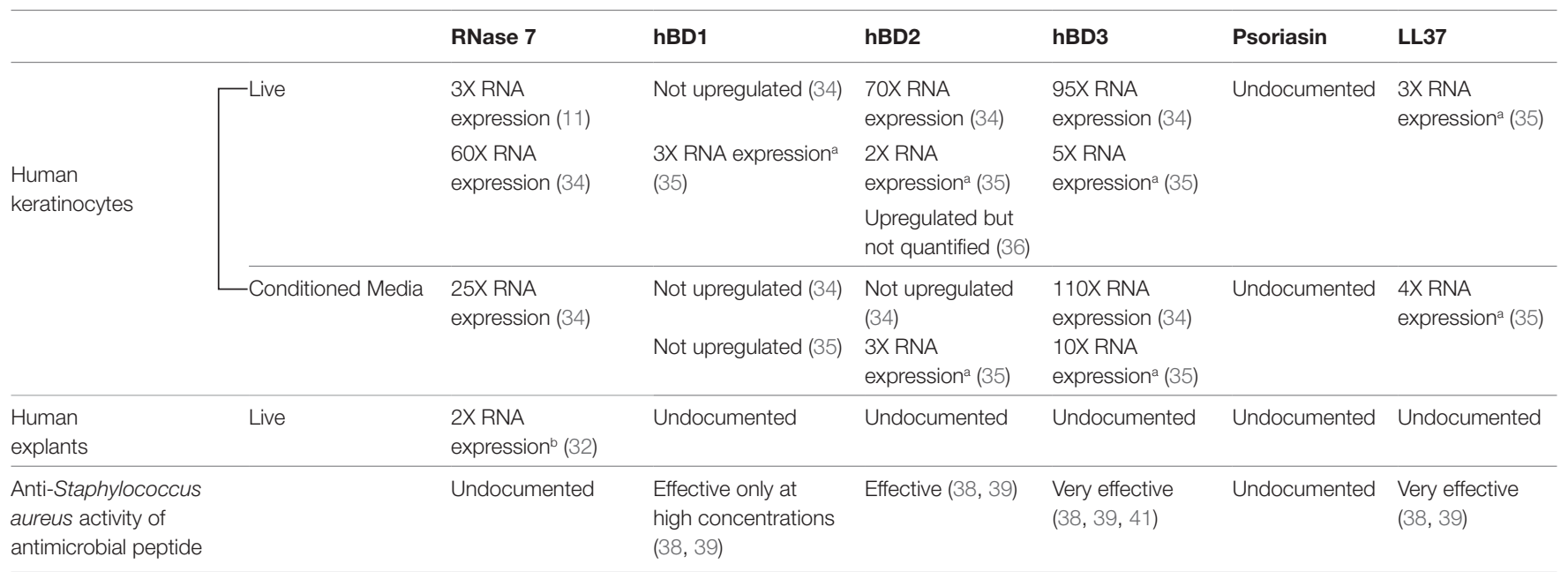

Several studies have noted the upregulation of RNase7, hBD2, hBD3 and LL37 following challenge by S. aureus on keratinocytes. However, the AMP Psoriasin has not been studied in this model, nor have the aforementioned studies validated their results on an ex vivo model. Additionally, hBD3 and LL37 kill S. aureus at lower concentrations than the others tested.

${ }^{a} \mathrm{Ca}^{2+}$ differentiated keratinocytes.

${ }^{b}$ Expression measured after $2 h$. 
upregulated LL-37 expression in sebocytes and it was shown to work synergistically with psoriasin (47). Additionally, different strains of $P$. acnes were shown to induce hBD2 expression in sebocytes (48).

\section{Other Microorganisms}

Various other bacteria and fungi have been shown to induce AMP expression in keratinocytes or other skin models. Pseudomonas fluorescens induces hBD2 and hBD3 expression in skin explants (43) and Pseudomonas aeruginosa can induce hBD2 and hBD3 expression in keratinocytes $(6,36)$. Escherichia coli infection of keratinocytes induces the expression of Psoriasin and of hBD2 $(6,36,49)$, while Acinetobacter baumannii induces $\mathrm{hBD} 2$ and $\mathrm{hBD} 3$ transcripts following infection of primary skin epithelial cells (50). Streptococcus pyogenes induces RNase 7 expression and certain strains can induce hBD2 expression $(11,36)$. Malassezia furfur can upregulate hBD2 and hBD3 expression in human keratinocytes $(51,52)$. Finally, Candida albicans induces hBD2 expression in primary keratinocytes (6). Of additional note, the vast majority of the aforementioned experiments were carried out on cell lines, with only a select few having been performed on skin explants.

\section{IN VITRO EFFICACY OF AMP IN BACTERIAL CLEARANCE}

Following the discovery of bacterial-induced skin AMP's, their efficacy in bacterial clearance in vitro was evaluated. Owing to differences in reporting standards, AMP efficacy results have been published using various different benchmarks and are therefore challenging to compare robustly to one another. An additional challenge in translating these studies are the differences between in vivo and in vitro salt concentrations and human topographical differences in salt concentrations owing to varied presence of sweat glands on the skin. Nevertheless, these studies are crucial in understanding the bacteria-modulating effects of AMPs. As per the focus of this article, we summarize AMP antimicrobial activity with regards to resident skin microorganisms exclusively.

Kisich et al., Chen et al., and Midorikawa et al. showed that LL-37 and hBD3 had significantly more anti-S. aureus activity than $\mathrm{hBD} 1$ and $\mathrm{hBD} 2$, and that the former two were effective in killing $99.9 \%$ of $S$. aureus in single-digit micromolar concentrations $(38,39,41)$. Elsewhere, $1.6 \mu \mathrm{mol}$ of LL-37 was reported to kill $50 \%$ of $S$. aureus $(53,54)$ and $50 \mu \mathrm{g} / \mathrm{ml}$ of LL-37 was shown to eradicate $80 \%$ of $S$. aureus (47). Ong et al. showed strong activity of LL-37 against clinical isolates of $S$. aureus from Atopic Dermatitis patients, while hBD2 was significantly less potent (25). Acidic pH sharply enhances the antibacterial capabilities of the three human beta-defensins, yet decreases that of LL-37 (39). Of particular relevance to the skin environment, hBD1, hBD2, and hBD3 are effective at low and physiologic salt concentrations (0-200 $\mathrm{mM} \mathrm{NaCl})$ (9). Additionally, AMPs often work synergistically with one another, allowing for better $S$. aureus clearance when administered/secreted in tandem (39). Of additional importance, certain AMPs can inhibit biofilm formation at subantimicrobial concentrations. For example, LL-37 inhibits $40 \%$ of $S$. aureus biofilm growth at a concentration well below its minimal inhibitory concentration (MIC) (54).

In addition, anti-S. epidermidis activity of skin AMP's has been studied in vitro. LL-37 kills $50 \%$ of S. epidermidis at a concentration of $1.3 \mu \mathrm{g} / \mathrm{ml}$ (53). LL-37 inhibits bacterial attachment and biofilm formation of $S$. epidermidis at subinhibitory concentrations (55). S. epidermidis exopolysaccharide intercellular adhesin provides a level of resistance to hBD3 and LL-37 (56). hBD2 harbors anti-S. epidermidis activity at single-digit micromolar concentrations (36), while Psoriasin can kill S. aureus and S. epidermidis in relatively high concentrations (10).

Certain AMPs are capable of inhibiting $P$. acnes growth as well. Lee et al. reported that $50 \mu \mathrm{g} / \mathrm{ml}$ of LL-37 was capable of clearing $95 \%$ of $P$. acnes (47). Furthermore, single micromolar concentrations of RNase 7 eradicate $P$. acnes growth (11).

\section{PERSPECTIVES/CONCLUSION}

Given the in vitro and ex vivo inducibility of AMP expression by skin microorganisms and their ability to effectively kill bacteria and fungal residents of the skin in vitro, it is crucial to determine AMP expression levels and their correlation with microbial expression patterns on the skin. Several studies have already painted a general picture of the biogeographical distribution of AMPs in healthy individuals (summarized in Figure 1). hBD1 and hBD2 expression, as measured by immunohistochemistry, are generally expressed at higher levels on the scalp and plantar surface than on the axilla, abdomen, and chest (57). hBD3 is highly expressed on the forehead, and lessso in other areas of the body (58). Psoriasin is secreted mostly on the face and head, as well as in the plantar heel and palm $(10,58)$. RNase 7 is highly expressed on the chest, abdomen, facial sites, and forearm $(58,59)$. While these early descriptive studies provided pioneering confirmation that skin AMP's were secreted in many body sites in healthy individuals and that their expression was site-dependant, further research must be done to strengthen our understanding of the AMP-microbe relationship. Microbiome studies have shown that skin bacterial and fungal communities are both site and age dependant $(17,60-62)$. Given the ability of specific microorganisms to induce certain AMPs, there is reason to believe that AMP expression both reflects and effects the composition of bacterial and fungal skin communities at different sites and at different ages. Tape-stripping, a non-invasive method of gathering AMPs for subsequent ELISA or western blotting quantification, could simultaneously be used to collect epidermal microorganisms for microbiome analysis. Our current research, which integrates microbial ecology profiling with AMP-specific ELISA protein quantification kits, posits that dysbiotic states are associated with an altered AMP milieu. We are specifically intrigued by diseased states with a known 


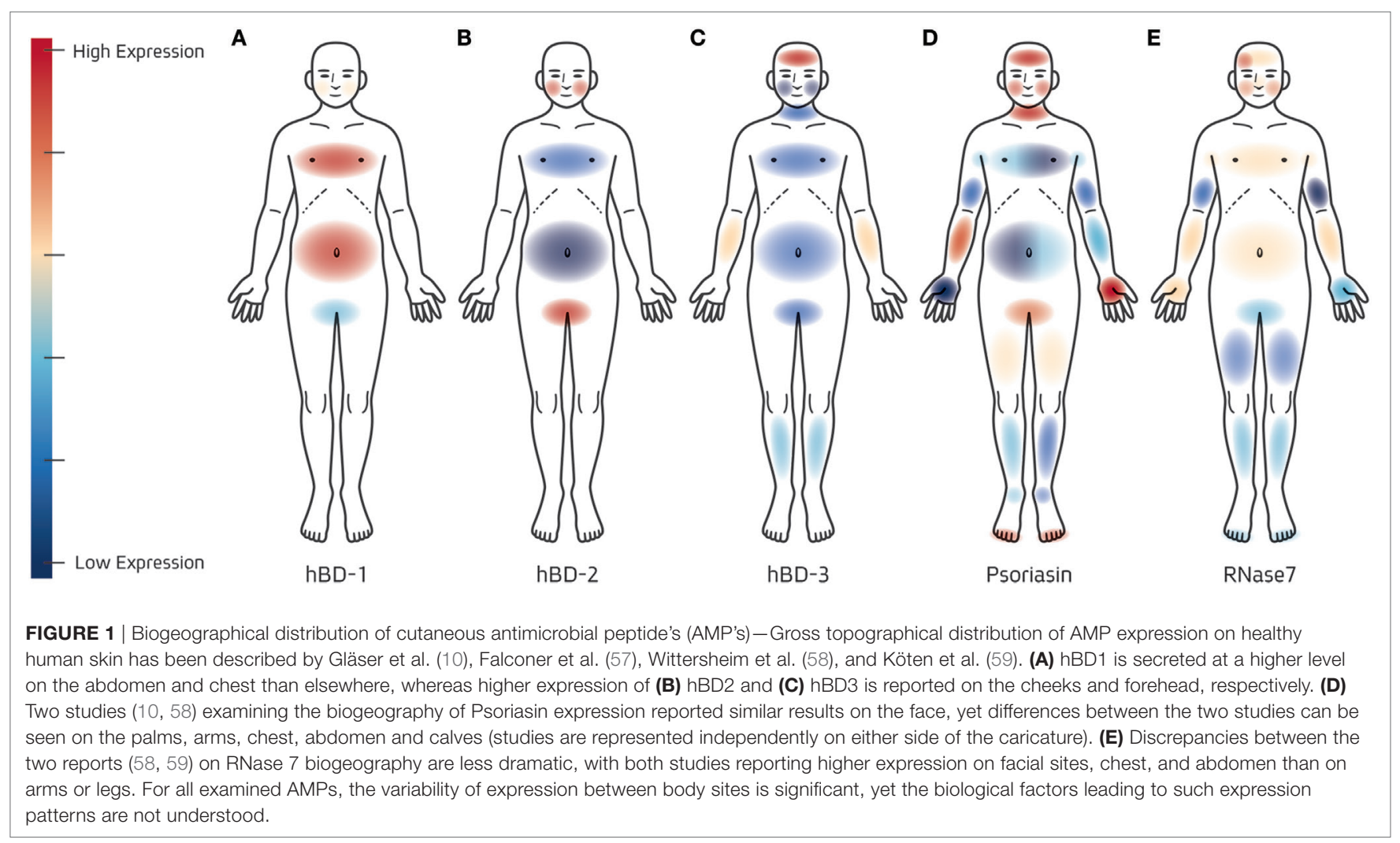

microbiological etiological factor, such as atopic dermatitis (dysbiosis dominated by $S$. aureus) or acne vulgaris (dysbiosis characterized by outgrowth of certain $P$. acnes strains). Such projects would be supported by recording and correlating various chemical attributes of the skin including sebum content, salinity, and moisture.

Furthermore, the aforementioned microbiome and metagenome studies have revealed a wide variety of microorganisms that are consistently found on the skin surface, yet have not received proper attention from the cutaneous microbiological community owing to their relative anonymity. Although such organisms remain understudied due to their non-pathogenic nature, their contribution toward community homeostasis and equilibrium cannot be ruled out. We therefore propose investigating their susceptibility to AMP exposure and their ability to induce AMP expression in relevant skin models.

Finally, in vitro studies of fungal skin residents have classically been dominated by the pathogenic fungi $M$. furfur and C. albicans. However, the aforementioned community-structure studies have revealed that the two species $M$. restricta and M. globosa comprise over $90 \%$ of the fungal skin flora. These two Malassezia species induce proinflammatory cytokine secretion following infection of keratinocytes, which is partly TLR-2 dependant, further strengthening the hypothesis that they can alter AMP expression as well (63). To the best of our knowledge, no article has addressed either the ability of skin AMPs to kill these two fungi or the ability of these fungi to induce AMP expression in vitro, ex vivo, or in vivo.

In conclusion, it is evidently clear that our skin cells are equipped with a broad arsenal of AMPs to mitigate the effects of pathogen colonization. However, our documentation of this phenomenon has largely been limited to known skin pathogens in in vitro models. We propose expanding the list of microorganisms studied to the myriad other bacteria and fungi that reside on our skin and emphasize the importance of validating such data on the skin explant model. Finally, we propose integrating microbiome-era knowledge into experimental design in an effort to obtain a more holistic and complete picture of skin AMP expression.

\section{AUTHOR CONTRIBUTIONS}

$\mathrm{MB}, \mathrm{ZB}$, and DS prepared the manuscript.

\section{FUNDING}

$\mathrm{MB}$ and $\mathrm{ZB}$ are supported by the Israel Ministry of Science, Technology and Space, grant no. 3-11174. MB is supported in part by The Kaete Klausner Fellowship. 


\section{REFERENCES}

1. Gallo RL. Human skin is the largest epithelial surface for interaction with microbes. J Investig Dermatol (2017) 137(6):1213-4. doi:10.1016/j. jid.2016.11.045

2. Kanitakis J. Anatomy, histology and immunohistochemistry of normal human skin. Eur J Dermatol (2002) 12(4):390-401.

3. Pasparakis M, Haase I, Nestle FO. Mechanisms regulating skin immunity and inflammation. Nat Rev Immunol (2014) 14(5):289-301. doi:10.1038/nri3646

4. Belkaid Y, Segre JA. Dialogue between skin microbiota and immunity. Science (2014) 346(6212):954-9. doi:10.1126/science.1260144

5. Niyonsaba F, Kiatsurayanon C, Chieosilapatham P, Ogawa H. Friends or Foes? Host defense (antimicrobial) peptides and proteins in human skin diseases. Exp Dermatol (2017) 26(11):989-98. doi:10.1111/exd.13314

6. Harder J, Bartels J, Christophers E, Schröder J-M. A peptide antibiotic from human skin. Nature (1997) 387(6636):861. doi:10.1038/43088

7. Nizet V, Ohtake T, Lauth X, Trowbridge J, Rudisill J, Dorschner RA, et al. Innate antimicrobial peptide protects the skin from invasive bacterial infection. Nature (2001) 414(6862):454-7. doi:10.1038/35106587

8. Frohm M, Agerberth B, Ahangari G, Ståhle-Bäckdahl M, Lidén S, Wigzell H, et al. The expression of the gene coding for the antibacterial peptide LL-37 is induced in human keratinocytes during inflammatory disorders. J Biol Chem (1997) 272(24):15258-63. doi:10.1074/jbc.272.24.15258

9. Harder J, Bartels J, Christophers E, Schröder J-M. Isolation and characterization of human $\beta$-defensin-3, a novel human inducible peptide antibiotic. J Biol Chem (2001) 276(8):5707-13. doi:10.1074/jbc.M008557200

10. Gläser R, Harder J, Lange H, Bartels J, Christophers E, Schröder J-M. Antimicrobial psoriasin (S100A7) protects human skin from Escherichia coli infection. Nat Immunol (2005) 6(1):57-64. doi:10.1038/ni1142

11. Harder J, Schröder J-M. RNase 7, a novel innate immune defense antimicrobial protein of healthy human skin. J Biol Chem (2002) 277(48):46779-84. doi:10.1074/jbc.M207587200

12. Schittek B, Hipfel R, Sauer B, Bauer J, Kalbacher H, Stevanovic S, et al. Dermcidin: a novel human antibiotic peptide secreted by sweat glands. Nat Immunol (2001) 2(12):1133-7. doi:10.1038/ni732

13. Izadpanah A, Gallo RL. Antimicrobial peptides. J Am Acad Dermatol (2005) 52(3):381-90. doi:10.1016/j.jaad.2004.08.026

14. Jann NJ, Schmaler M, Kristian SA, Radek KA, Gallo RL, Nizet V, et al. Neutrophil antimicrobial defense against Staphylococcus aureus is mediated by phagolysosomal but not extracellular trap-associated cathelicidin. J Leukoc Biol (2009) 86(5):1159-69. doi:10.1189/jlb.0209053

15. Ryu S, Song PI, Seo CH, Cheong H, Park Y. Colonization and infection of the skin by $S$. aureus: immune system evasion and the response to cationic antimicrobial peptides. Int J Mol Sci (2014) 15(5):8753-72. doi:10.3390/ ijms15058753

16. Grice EA, Kong HH, Conlan S, Deming CB, Davis J, Young AC, et al. Topographical and temporal diversity of the human skin microbiome. Science (2009) 324(5931):1190-2. doi:10.1126/science.1171700

17. Oh J, Byrd AL, Deming C, Conlan S, Kong HH, Segre JA, et al. Biogeography and individuality shape function in the human skin metagenome. Nature (2014) 514(7520):59-64. doi:10.1038/nature13786

18. Oh J, Byrd AL, Park M; NISC Comparative Sequencing Program, Kong HH, Segre JA. Temporal stability of the human skin microbiome. Cell (2016) 165(4):854-66. doi:10.1016/j.cell.2016.04.008

19. Brandwein M, Steinberg D, Meshner S. Microbial biofilms and the human skin microbiome. NPJ Biofilms Microbiomes (2016) 2(1):3. doi:10.1038/ s41522-016-0004-Z

20. Kong HH, Oh J, Deming C, Conlan S, Grice EA, Beatson MA, et al. Temporal shifts in the skin microbiome associated with disease flares and treatment in children with atopic dermatitis. Genome Res (2012) 22(5):850-9. doi:10.1101/gr.131029.111

21. Williams HC, Dellavalle RP, Garner S. Acne vulgaris. Lancet (2012) 379(9813):361-72. doi:10.1016/S0140-6736(11)60321-8

22. Yamasaki K, Di Nardo A, Bardan A, Murakami M, Ohtake T, Coda A, et al. Increased serine protease activity and cathelicidin promotes skin inflammation in rosacea. Nat Med (2007) 13(8):975-80. doi:10.1038/nm1616

23. Harder J, Schröder J-M. Psoriatic scales: a promising source for the isolation of human skin-derived antimicrobial proteins. JLeukoc Biol (2005) 77(4): 476-86. doi:10.1189/jlb.0704409
24. Hollox EJ, Huffmeier U, Zeeuwen PL, Palla R, Lascorz J, Rodijk-Olthuis D, et al. Psoriasis is associated with increased beta-defensin genomic copy number. Nat Genet (2008) 40(1):23. doi:10.1038/ng.2007.48

25. Ong PY, Ohtake T, Brandt C, Strickland I, Boguniewicz M, Ganz T, et al. Endogenous antimicrobial peptides and skin infections in atopic dermatitis. N Engl J Med (2002) 347(15):1151-60. doi:10.1056/NEJMoa021481

26. de Jongh GJ, Zeeuwen PL, Kucharekova M, Pfundt R, van der Valk PG, Blokx W, et al. High expression levels of keratinocyte antimicrobial proteins in psoriasis compared with atopic dermatitis. J Investig Dermatol (2005) 125(6):1163-73. doi:10.1111/j.0022-202X.2005.23935.x

27. Nomura I, Goleva E, Howell MD, Hamid QA, Ong PY, Hall CF, et al. Cytokine milieu of atopic dermatitis, as compared to psoriasis, skin prevents induction of innate immune response genes. J Immunol (2003) 171(6):3262-9. doi:10.4049/jimmunol.171.6.3262

28. Howell MD, Boguniewicz M, Pastore S, Novak N, Bieber T, Girolomoni G, et al. Mechanism of HBD-3 deficiency in atopic dermatitis. Clin Immunol (2006) 121(3):332-8. doi:10.1016/j.clim.2006.08.008

29. Takahashi T, Gallo RL. The critical and multifunctional roles of antimicrobial peptides in dermatology. Dermatol Clin (2017) 35(1):39-50. doi:10.1016/j. det.2016.07.006

30. Schauber J, Gallo RL. Expanding the roles of antimicrobial peptides in skin: alarming and arming keratinocytes. J Investig Dermatol (2007) 127(3):510-2. doi:10.1038/sj.jid.5700761

31. Popov L, Kovalski J, Grandi G, Bagnoli F, Amieva MR. Three-dimensional human skin models to understand Staphylococcus aureus skin colonization and infection. Front Immunol (2014) 5:41. doi:10.3389/fimmu.2014.00041

32. Simanski M, Dressel S, Gläser R, Harder J. RNase 7 protects healthy skin from Staphylococcus aureus colonization. J Investig Dermatol (2010) 130(12): 2836-8. doi:10.1038/jid.2010.217

33. Zhang J, Dyer KD, Rosenberg HF. Human RNase 7: a new cationic ribonuclease of the RNase A superfamily. Nucleic Acids Res (2003) 31(2):602-7. doi:10.1093/nar/gkg157

34. Wanke I, Steffen H, Christ C, Krismer B, Götz F, Peschel A, et al. Skin commensals amplify the innate immune response to pathogens by activation of distinct signaling pathways. J Investig Dermatol (2011) 131(2): 382-90. doi:10.1038/jid.2010.328

35. Menzies BE, Kenoyer A. Staphylococcus aureus infection of epidermal keratinocytes promotes expression of innate antimicrobial peptides. Infect Immun (2005) 73(8):5241-4. doi:10.1128/IAI.73.8.5241-5244.2005

36. Dinulos JG, Mentele L, Fredericks LP, Dale BA, Darmstadt GL. Keratinocyte expression of human $\beta$ defensin 2 following bacterial infection: role in cutaneous host defense. Clin Diagn Lab Immunol (2003) 10(1):161-6. doi:10.1128/ CDLI.10.1.161-166.2003

37. Menzies BE, Kenoyer A. Signal transduction and nuclear responses in Staphylococcus aureus-induced expression of human $\beta$-defensin 3 in skin keratinocytes. Infect Immun (2006) 74(12):6847-54. doi:10.1128/IAI.00389-06

38. Midorikawa K, Ouhara K, Komatsuzawa H, Kawai T, Yamada S, Fujiwara T, et al. Staphylococcus aureus susceptibility to innate antimicrobial peptides, $\beta$-defensins and CAP18, expressed by human keratinocytes. Infect Immun (2003) 71(7):3730-9. doi:10.1128/IAI.71.7.3730-3739.2003

39. Chen X, Niyonsaba F, Ushio H, Okuda D, Nagaoka I, Ikeda S, et al. Synergistic effect of antibacterial agents human $\beta$-defensins, cathelicidin LL-37 and lysozyme against Staphylococcus aureus and Escherichia coli. J Dermatol Sci (2005) 40(2):123-32. doi:10.1016/j.jdermsci.2005.03.014

40. Iwase T, Uehara Y, Shinji H, Tajima A, Seo H, Takada K, et al. Staphylococcus epidermidis Esp inhibits Staphylococcus aureus biofilm formation and nasal colonization. Nature (2010) 465(7296):346-9. doi:10.1038/ nature 09074

41. Kisich KO, Howell MD, Boguniewicz M, Heizer HR, Watson NU, Leung DY. The constitutive capacity of human keratinocytes to kill Staphylococcus aureus is dependent on $\beta$-defensin 3. J Investig Dermatol (2007) 127(10): 2368-80. doi:10.1038/sj.jid.5700861

42. Braff MH, Zaiou M, Fierer J, Nizet V, Gallo RL. Keratinocyte production of cathelicidin provides direct activity against bacterial skin pathogens. Infect Immun (2005) 73(10):6771-81. doi:10.1128/IAI.73.10.6771-6781.2005

43. Percoco G, Merle C, Jaouen T, Ramdani Y, Bénard M, Hillion M, et al. Antimicrobial peptides and pro-inflammatory cytokines are differentially regulated across epidermal layers following bacterial stimuli. Exp Dermatol (2013) 22(12):800-6. doi:10.1111/exd.12259 
44. Lai Y, Cogen AL, Radek KA, Park HJ, MacLeod DT, Leichtle A, et al. Activation of TLR2 by a small molecule produced by Staphylococcus epidermidis increases antimicrobial defense against bacterial skin infections. J Investig Dermatol (2010) 130(9):2211-21. doi:10.1038/jid.2010.123

45. Nagy I, Pivarcsi A, Koreck A, Széll M, Urbán E, Kemény L. Distinct strains of Propionibacterium acnes induce selective human $\beta$-defensin-2 and interleukin-8 expression in human keratinocytes through toll-like receptors. J Investig Dermatol (2005) 124(5):931-8. doi:10.1111/j.0022-202X.2005. 23705.x

46. Lee SE, Kim J-M, Jeong SK, Jeon JE, Yoon H-J, Jeong M-K, et al. Proteaseactivated receptor- 2 mediates the expression of inflammatory cytokines, antimicrobial peptides, and matrix metalloproteinases in keratinocytes in response to Propionibacterium acnes. Arch Dermatol Res (2010) 302(10):74556. doi:10.1007/s00403-010-1074-z

47. Lee D-Y, Yamasaki K, Rudsil J, Zouboulis CC, Park GT, Yang J-M, et al. Sebocytes express functional cathelicidin antimicrobial peptides and can act to kill Propionibacterium acnes. J Invest Dermatol (2008) 128(7):1863. doi:10.1038/sj.jid.5701235

48. Nagy I, Pivarcsi A, Kis K, Koreck A, Bodai L, McDowell A, et al. Propionibacterium acnes and lipopolysaccharide induce the expression of antimicrobial peptides and proinflammatory cytokines/chemokines in human sebocytes. Microbes Infect (2006) 8(8):2195-205. doi:10.1016/j. micinf.2006.04.001

49. Abtin A, Eckhart L, Mildner M, Gruber F, Schröder J-M, Tschachler E. Flagellin is the principal inducer of the antimicrobial peptide S100A7c (psoriasin) in human epidermal keratinocytes exposed to Escherichia coli. FASEB J (2008) 22(7):2168-76. doi:10.1096/fj.07-104117

50. Feng Z, Jia X, Adams MD, Ghosh SK, Bonomo RA, Weinberg A. Epithelial innate immune response to Acinetobacter baumannii challenge. Infect Immun (2014) 82(11):4458-65. doi:10.1128/IAI.01897-14

51. Donnarumma G, Paoletti I, Buommino E, Orlando M, Tufano MA, Baroni A. Malassezia furfur induces the expression of $\beta$-defensin- 2 in human keratinocytes in a protein kinase C-dependent manner. Arch Dermatol Res (2004) 295(11):474-81. doi:10.1007/s00403-003-0445-0

52. Baroni A, Orlando M, Donnarumma G, Farro P, Iovene MR, Tufano MA, et al. Toll-like receptor 2 (TLR2) mediates intracellular signalling in human keratinocytes in response to Malassezia furfur. Arch Dermatol Res (2006) 297(7):280. doi:10.1007/s00403-005-0594-4

53. Gordon YJ, Huang LC, Romanowski EG, Yates KA, Proske RJ, McDermott AM. Human cathelicidin (LL-37), a multifunctional peptide, is expressed by ocular surface epithelia and has potent antibacterial and antiviral activity. Curr Eye Res (2005) 30(5):385-94. doi:10.1080/02713680590934111

54. Dean SN, Bishop BM, van Hoek ML. Natural and synthetic cathelicidin peptides with anti-microbial and anti-biofilm activity against Staphylococcus aureus. BMC Microbiol (2011) 11(1):114. doi:10.1186/1471-2180-11-114
55. Hell E, Giske C, Nelson A, Römling U, Marchini G. Human cathelicidin peptide LL37 inhibits both attachment capability and biofilm formation of Staphylococcus epidermidis. Lett Appl Microbiol (2010) 50(2):211-5. doi:10.1111/j.1472-765X.2009.02778.x

56. Vuong C, Voyich JM, Fischer ER, Braughton KR, Whitney AR, DeLeo FR, et al. Polysaccharide intercellular adhesin (PIA) protects Staphylococcus epidermidis against major components of the human innate immune system. Cell Microbiol (2004) 6(3):269-75. doi:10.1046/j.1462-5822.2004. 00367.x

57. Falconer A, Ikram M, Bissett CE, Cerio R, Quinn AG, Ali RS. Expression of the peptide antibiotics human $\beta$ defensin- 1 and human $\beta$ defensin- 2 in normal human skin. J Investig Dermatol (2001) 117(1):106-11. doi:10.1046/j. 0022-202x.2001.01401.x

58. Wittersheim M, Cordes J, Meyer-Hoffert U, Harder J, Hedderich J, Gläser R. Differential expression and in vivo secretion of the antimicrobial peptides psoriasin (S100A7), RNase 7, human beta-defensin-2 and -3 in healthy human skin. Exp Dermatol (2013) 22(5):364-6. doi:10.1111/exd. 12133

59. Köten B, Simanski M, Gläser R, Podschun R, Schröder J-M, Harder J. RNase 7 contributes to the cutaneous defense against Enterococcus faecium. PLoS One (2009) 4(7):e6424. doi:10.1371/journal.pone.0006424

60. Jo J-H, Deming C, Kennedy EA, Conlan S, Polley EC, Ng W-L, et al Diverse human skin fungal communities in children converge in adulthood. J Investig Dermatol (2016) 136(12):2356-63. doi:10.1016/j.jid.2016.05.130

61. Grice EA, Kong HH, Renaud G, Young AC, Bouffard GG, Blakesley RW, et al. A diversity profile of the human skin microbiota. Genome Res (2008) 18(7):1043-50. doi:10.1101/gr.075549.107

62. Findley K, Oh J, Yang J, Conlan S, Deming C, Meyer JA, et al. Topographic diversity of fungal and bacterial communities in human skin. Nature (2013) 498(7454):367-70. doi:10.1038/nature12171

63. Donnarumma G, Perfetto B, Paoletti I, Oliviero G, Clavaud C, Del Bufalo A, et al. Analysis of the response of human keratinocytes to Malassezia globosa and restricta strains. Arch Dermatol Res (2014) 306(8):763-8. doi:10.1007/ s00403-014-1479-1

Conflict of Interest Statement: The authors declare that the research was conducted in the absence of any commercial or financial relationships that could be construed as a potential conflict of interest.

Copyright (C) 2017 Brandwein, Bentwich and Steinberg. This is an open-access article distributed under the terms of the Creative Commons Attribution License (CC BY). The use, distribution or reproduction in other forums is permitted, provided the original author(s) or licensor are credited and that the original publication in this journal is cited, in accordance with accepted academic practice. No use, distribution or reproduction is permitted which does not comply with these terms. 